\title{
Macroscopic Cardiac Changes in Antipsychotic Therapy
}

\author{
Volkov VP* \\ Tver center of judicial examinations, Russia
}

*Corresponding author: Volkov VP, Tver center of judicial examinations, 170008, A Zavidov St, 24 of 6 Tver, Russia.

To Cite This Article: Volkov VP. Macroscopic Cardiac Changes in Antipsychotic Therapy. Am J Biomed Sci \& Res. 2019 - 3(3). AJBSR.MS.ID.000661. DOI: 10.34297/AJBSR.2019.03.000661

Received: May 08, 2019 | Published: June 06, 2019

\begin{abstract}
By a morphometric method of research, the macroscopic changes of the heart in the process of antipsychotic therapy was determined. The study of the effect of this therapy on the heart showed that changes in the organ at the macroscopic level of its organization develop gradually during the first ten years of treatment, after which they quickly reach almost the maximum and practically do not progress in the future. This reflects a significant reduction in the rate of cardiac remodeling at the organ level, as well as the foreground of microstructural myocardial damage.
\end{abstract}

Keywords: Antipsychotics, Cardiotoxicity; Duration of Antipsychotic Therapy; Pathomorphology Of Heart; Organ Level of Organization; Morphometry

Abbrevations: AD: Antipsychotic (Neuroleptic) Drugs; APT: Antipsychotic Therapy; RN: Relative Norm; m: Heart Mass; V: Volume of Heart; Cv: Coefficient of Volume; Cl: Coefficient of The Left Ventricle; MVR: Mass-Volume Ratio; IDM: Index of Density of Myocardium; M $\Delta$ : increase in the value of the indicator compared to $\mathrm{RN}$

\section{Introduction}

It is established that all $\mathrm{AD}$, both typical and atypical, have to some extent the property of cardiotoxicity [1-3]. However, the morphological changes of the heart at different levels of its organization (organ, tissue, cellular), developing in APT, practically not studied. Therefore, the aim of this work was to study such changes at the organ level of the heart organization.

\section{Material and Methods}

It is known that a quantitative morphologic characteristic of changes of each organ in the case of its any pathology must start from a definite "reference point" which is defined by the concept of a "norm" [4]. Therefore at the research beginning the results of autopsy protocols of 100 persons (50 men and 50 women) in the age from 18 to 82 years were analyzed who died from noncardiac causes and who did not have any accompanying cardiac pathology and this fact was verified by autopsy (group I). The cardiac parameters, which were received in this group, are taken as a relative norm (RN).

Then autopsy protocols of 70 patients with schizophrenia (41 men and 29 women) who died at the age from 22 to 77 years were analyzed. The final diagnosis of each deceased was verified at the autopsy.
The criteria of an exception were the expressed signs of a metabolic syndrome (the increased body weight, arterial hypertension, a diabetes mellitus), a chronic pulmonary pathology with hypertension in a small circle of blood circulation, a cachexia.

During their lives the patients received various $\mathrm{AD}$ in quantities corresponding to the therapeutic standard; these medicines are not rarely received in combination with each other. The duration of APT ranged from six months to 30 years or more.

Depending on the duration of the APT material is divided into four groups (II-V): II - up to ten years (20 dead); III - from 11 to 20 years (25); IV - from 21 to 30 years (19); V - over 30 years (6).

According to the modern doctrine of morphology as a science, a merely descriptive method of research is not enough for a correct and objective characteristic of pathologic changes being observed; it is strongly necessary to use objective criteria of functional morphology $[5,6]$ and to be guided by the principle of unity of pathology on various research levels; this principle was postulated by G.G. Avtandilov [6] in the past.

Therefore it seems actual to research a macroscopic condition of heart in APT by use of morphometric research methods which 
meet modern requirements of the evidence-based medicine $[7,8]$ and allow to objectivize the received results and the made conclusions, because final values of the parameters, which are studied, have the quantitative form and can sufficiently easily be analyzed statistically $[5,6]$.

For this reason, the original author's method developed by me for such studies [9] was used for the analysis of the obtained data.

The following parameters were measured on the macroscopic level: heart mass (m), linear dimensions, perimeter of venous valve openings, and thickness of a wall of ventricles.

For this analysis the outer volume of heart without atria (V) was determined and two relative parameters (both in percent) were calculated: 1) $\mathrm{Cv}$ - coefficient of volume, this coefficient shows a part of the total volume of heart (without atria), and this part falls on the volume of cavities of ventricles; and 2) $\mathrm{Cl}$ - coefficient of the left ventricle, this coefficient shows the volume size of the left ventricle with respect to the total volume of both ventricles. In addition, two other parameters were calculated which use a gravimetric characteristic of the heart $(\mathrm{m})$ : mass-volume ratio (MVR) and index of density of myocardium (IDM).

A growth of MVR is evidence of a hypertrophy of myocardium, and its diminution is an indication for dilatation of cavities of heart ventricles. IDM clearly shows a strongly expressed correlation with such objective parameters of microstructure of cardiac muscle as stromal-parenchymatous ratio and rate of interstitial edema [9], which quantitatively describe a condition of its intercellular matrix.

The obtained quantitative results were processed statistically (computer program "Statistica 6.0") with the level of significance of differences of $95 \%$ and more $(\mathrm{p} \leq 0.05)$.

\section{Results and discussion}

Macroscopic changes of the heart in the process of APT are presented in (Table 1).

\begin{tabular}{|c|c|c|c|c|c|c|}
\hline Indicators & $m$ & & & & & \\
\hline Groups & $\mathbf{m}$ & $v$ & $K_{o}$ & $\mathbf{K}_{\text {л }}$ & MOC & ИІІМ \\
\hline I & $\begin{array}{c}300 \pm 3 \\
2-5\end{array}$ & $\begin{array}{c}131,6 \pm 6,1 \\
2-5\end{array}$ & $\begin{array}{c}32,1 \pm 0,5 \\
2-5\end{array}$ & $\begin{array}{c}39,1 \pm 0,6 \\
3-5\end{array}$ & $\begin{array}{c}2,28 \pm 0,04 \\
3-5\end{array}$ & $\begin{array}{c}4,42 \pm 0,08 \\
2-5\end{array}$ \\
\hline II & $\begin{array}{r}317 \pm 7 \\
1,3-5\end{array}$ & $\begin{array}{c}141,4 \pm 5,4 \\
1,3-5\end{array}$ & $\begin{array}{c}34,5 \pm 0,6 \\
1,3-5\end{array}$ & $\begin{array}{c}39,7 \pm 0,6 \\
5\end{array}$ & $\begin{array}{c}2,24 \pm 0,04 \\
3-5\end{array}$ & $\begin{array}{c}4,57 \pm 0,08 \\
1,3-5\end{array}$ \\
\hline III & $\begin{array}{c}355 \pm 8 \\
1,2 \\
\end{array}$ & $\begin{array}{c}163,5 \pm 5,8 \\
1,2\end{array}$ & $41,4 \pm 0,41,2,4,5$ & $\begin{array}{c}40,2 \pm 0,5 \\
1\end{array}$ & $\begin{array}{c}2,17 \pm 0,04 \\
1,2\end{array}$ & $6,06 \pm 0,07 \quad 1,2,4,5$ \\
\hline IV & $\begin{array}{c}359 \pm 8 \\
1,2 \\
\end{array}$ & $\begin{array}{c}166,7 \pm 6,3 \\
1,2\end{array}$ & $\begin{array}{c}42,6 \pm 0,5 \\
1-3,5\end{array}$ & $\begin{array}{c}40,4 \pm 0,4 \\
1\end{array}$ & $\begin{array}{c}2,15 \pm 0,04 \\
1,2\end{array}$ & $\begin{array}{c}6,29 \pm 0,04 \\
1-3,5\end{array}$ \\
\hline V & $\begin{array}{c}364 \pm 5 \\
1,2\end{array}$ & $\begin{array}{c}168,7 \pm 6,3 \\
1,2\end{array}$ & $\begin{array}{c}43,8 \pm 0,6 \\
1-4\end{array}$ & $40,8 \pm 0,41,2$ & $\begin{array}{c}2,16 \pm 0,03 \\
1,2\end{array}$ & $\begin{array}{c}6,38 \pm 0,06 \\
1-4 \\
\end{array}$ \\
\hline
\end{tabular}

Note: 1-5 - statistically significant differences between the groups.

The study of macroscopic parameters of the heart and the indices calculated on their basis showed the change of all these values observed in the process of APT. Moreover, in a relatively early period of treatment (group II) from RN statistically significantly different four of the six indicators (excluding $\mathrm{Cl}$ and MVR). In the future, that is, ten years after the start of APT, these differences relate to all the studied organometric parameters, which allows us to consider the ten-year period of APT as a certain threshold, upon reaching which the increasing quantitative macroscopic changes in the heart pass into a new quality.

Such a circumstance should also be noted. With a sufficiently long (over 20 years) use of $\mathrm{AD}$ (group IV-V), 2/3 of macroscopic parameters, except for $\mathrm{CV}$ and IDM, remain practically constant. It turns out that in the first ten years of APT changes of the heart at the organ level develop gradually, and then quickly reach almost maximum. Subsequently, they continue in the same direction, but only at the level of the trend.
This applies primarily to parameters such as $\mathrm{m}$ and $\mathrm{V}$, which increase in the described rhythm is very significant ( $M \Delta$ is respectively $21.3 \%$ and $28.2 \%$ ), which indicates the development of cardiomegaly during APT. Moreover, the process of dilation in comparison with the phenomena of cardiac hypertrophy prevails to a certain extent, as evidenced, firstly, by a higher lability V compared to $\mathrm{m}$ and, secondly, even if not very pronounced, but progressive decrease in the values of MVR [9].

The ventricles of the heart are mainly subject to expansion, which is documented by a steady and significant increase in $\mathrm{Cv}(\mathrm{M} \Delta$ reaches $36.4 \%$ ). The index of $\mathrm{Cl}$ also increases, but the intensity of the dynamics of this process is almost an order of magnitude lower than that of $\mathrm{Cv}(\mathrm{M} \Delta$ only $4.3 \%)$. This document a more or less uniform expansion of both ventricles with only some predominance of left dilation only in the later stages of APT.

Most notably a steady increase in the values of IDM in relation to which the $\mathrm{M} \Delta$ ultimately translates to $44.3 \%$. This fact indirectly 
reflects the development of significant stromal myocardial changes [9] occurring at the microscopic level in conjunction with other pathological changes.

\section{Conclusion}

The study of the effect of APT on the heart showed that changes in the organ at the macroscopic level of its organization develop gradually during the first ten years of APT, after which they quickly reach almost the maximum and practically do not progress in the future. This reflects, if not the cessation, then a significant decrease in the rate of cardiac remodeling at the organ level, and a rise to the forefront in the development of myocardial dysfunction of microstructural myocardial damage.

\section{References}

1. Volkov VP (2018) Cardiotoxicity of neuroleptics: clinical aspects. Beau Bassin LAP Lambert Academic Publ, Germany.

2. Buckley NA, Sanders P (200) Cardiovascular adverse effects of antipsychotic drugs. Drug Saf 23(3): 215-228.
3. Mackin P (2008) Cardiac side effects of psychiatric drugs. Hum Psychopharmacol 23(Suppl 1): 3-14.

4. Petlenko VP, Tsaregorodtsev GI (1979) Philosophy of medicine. Kiev Zdorovja Publ.

5. Avtandilov GG (1990) Medical morphometry: management. Moscow Medicine Publ.

6. Avtandilov GG (2002) Fundamentals of quantitative pathological anatomy. Moscow Medicine Publ.

7. Grinkhalkh T (2004) The basics of evidence-based medicine / lane with English. Moscow GEOTAR-MED Publ.

8. Klyushin DA, Petunin YuI (2008) Evidential medicine. Application of statistical methods. Moscow Dialectics Publ.

9. Volkov VP (2014) New method of an organometry of heart. In: Paraklinicheskie discipliny: novye metody i diagnosticheskie vozmozhnosti: kollektivnaya monografiya / pod red Novosibirsk: SiBAK Publ pp. 78-100. 